\title{
Consumer Reaction to the Great East Japan Earthquake
}

\author{
Takashi Ishida, Atsushi Maruyama and Shinichi Kurihara \\ Graduate School of Horticulture, Chiba University, Matsudo 271-8510, Chiba, Japan
}

Received: April 07, 2013 / Accepted: June 14, 2013 / Published: August 30, 2013.

\begin{abstract}
Following the Great East Japan Earthquake in March 2011, the demand for bottled water increased sharply. In this paper, the authors analyze who purchased more bottled water after the earthquake using Quick Purchase Report data. The results are as follows: first, consumers who before the earthquake tended to purchase less bottled water tended to increase the volume purchased after the earthquake; second, the motives for purchasing bottled water after the earthquake differed between consumers in the Tokyo and Osaka metropolitan districts.
\end{abstract}

Key words: Bottled water, purchasing behavior, Great East Japan Earthquake, hoarding.

\section{Introduction}

The Great East Japan Earthquake on March 11, 2011 had a major impact on the purchasing behavior of Japanese consumers. For example, consumers in Japan began to hoard food and daily-use commodities, and the post-earthquake mood of restraint resulted in a decline in spending on eating out. Table 1 details the total amounts of expenditure in March 2011 on those items subjected to the greatest influence from the earthquake and the percent change from the same month in the previous year. It can be seen that after the earthquake, expenditure increased for the following goods: nonperishable foods, such as cup and instant noodles, canned goods, and bottled water; cassette-type gas ranges; and daily-use commodities, including tissue paper, rolled toilet paper, and dry batteries. In contrast, the table also shows that expenditure on eating out declined.

One item for which purchases substantially increased following the earthquake was bottled water. Following the accident at the Fukushima No. 1

Corresponding author: Takashi Ishida, Ph.D., assistant professor, research field: consumer behavior analysis. E-mail: t.ishida@chiba-u.jp.

1 Japan's Food Sanitation Act defines the safe level of radioactive iodine per kilogram of water or milk as 300 becquerels for adults and 100 becquerels for infants. nuclear power plant, 210 becquerels of radioactive iodine per kilogram of water, which was above the safety standard for infants, was detected at a water purification plant located in Tokyo. This resulted in the absence of bottled water on supermarket shelves ${ }^{1}$. Consumer reactions to the natural disaster are also analyzed [1, 2].

This paper analyzed who purchased more bottled water around the time of the earthquake using scanned individual data. If the authors can identify the effect that the earthquake had on consumer purchasing behavior, this information to specify the clusters of consumers that tend to change their purchasing behavior significantly during a disaster can be used. This can provide important information when considering disaster management policies, such as the distribution of food ${ }^{2}$.

The structure of the paper is as follows. In the second section, this paper reviews related literatures and formulate a hypothesis about hoarding behavior; in the third section, the authors introduce the data and model used in the paper; in the fourth section, this paper estimates the model and discuss the results; in the fifth and final section, the paper is concluded.

\footnotetext{
${ }^{2}$ Quality of emergency provisions is also important. It is analyzed that the consumer accept it [3].
} 
Table 1 Items significantly affected by consumer-purchasing behavior.

\begin{tabular}{|c|c|c|c|c|}
\hline Item & & $\begin{array}{l}\text { March } \\
2010\end{array}$ & $\begin{array}{l}\text { March } \\
2011\end{array}$ & $\begin{array}{l}\text { Percent change from the same } \\
\text { month in the previous year }\end{array}$ \\
\hline \multirow{6}{*}{ Food } & Cup noodles & 316 & 443 & $40 \%$ \\
\hline & Instant noodles & 158 & 206 & $30 \%$ \\
\hline & Canned fish & 191 & 267 & $40 \%$ \\
\hline & Instant dried soup & 209 & 273 & $31 \%$ \\
\hline & Bottled water & 160 & 397 & $148 \%$ \\
\hline & Eating and drinking out & 12409 & 10254 & $-17 \%$ \\
\hline \multirow{4}{*}{ Livingware } & Gas cooking appliances & 95 & 197 & $107 \%$ \\
\hline & Facial tissue & 194 & 249 & $28 \%$ \\
\hline & Rolled toilet paper & 260 & 342 & $32 \%$ \\
\hline & Dry battery & 140 & 396 & $183 \%$ \\
\hline
\end{tabular}

Source: Family Income and Expenditure Survey;

Note: Gas cooking appliances includes cassette-type gas ranges.

\section{Literature Review and Hypothesis}

There is some background literature concerning serious shortages of commodities during natural and other disasters. The first relates to the increase in demand for the commodity itself. It is considered that consumers changed from tap water to bottled water in order to avoid any health risks posed by radioactive substances, which resulted in an increase in the demand for bottled water. Moreover, Sneath [4] pointed out that the victims of Hurricane Katrina exhibited irrational purchasing behavior, such as making emotional purchases for items that they did not really need or that they would not normally buy. Therefore, the increase of bottled water purchases after the earthquake could not only be due to the desire of consumers to avoid health risks posed by contaminated tap water, but also a desire for hoarding as they bought more than they needed because of their vague anxiety and fears about shortages in the future.

Inventory accumulation can classified into four types; namely, investment, speculation, safety stock, and hoarding, based on two axes [5]. The first is whether the inventory accumulation is for profit seeking or loss-aversion; the second is whether the purchases involved differed from ordinary purchasing behavior. According to this classification, the definitions of each type of inventory accumulation are as follows. First, bulk purchases of items on sale characterize investment in inventory accumulation, even though these items may not be required for many months. Second, a purchase of more than needed to resell at a higher price in anticipation of a future price increase characterizes speculation in inventory accumulation. Third, purchases to avoid frustration associated with the cost of frequent shopping and stock outs of necessary items characterize safety stock in inventory accumulation. Finally, the purchase of more items than required, in which the dominant motivation is to avoid the fear that they will sell out in the future, characterizes hoarding in inventory accumulation.

Thus, it can be classified investment and speculation as the profit-seeking type of inventory accumulation, and safety stock and hoarding as the loss-aversion type of inventory accumulation. In addition, compared with investment and safety stock, speculation and hoarding are a form of inventory accumulation that differs markedly from ordinary purchasing behavior. For the most part, the authors find that hoarding-motivated purchases, compared with other patterns of purchase, are based on emotion and consumers engaged in hoarding perceive that there is a high risk that a commodity will run out in the future, and therefore purchase extraordinary volumes of the chosen commodity. 
Unfortunately, it is difficult to distinguish purchases because of an increase in demand for a product from hoarding due to vague anxiety or consumer fears about product shortages in the future solely from market data. However, by recognizing what type of consumer increased their purchases of bottled water after the earthquake, the authors can speculate upon the structure of changes in volumes purchased.

What kind of relationship then exists between the risk perception of drinking tap water and the consumer's characteristics? There are several studies that have analyzed the variation in risk perceived by consumers associated with social demographic factors [6-9]. Table 2 summarizes the results of previous studies on the impact of social demographic factors on perceptions of risk. In this table, "+" indicates that these factors are positively correlated with the risk perceptions of consumers; "N.S." indicates that no significant effect is observed; "U.S." indicates that the effect is unstable, and a blank space indicates that the variable has not been analyzed. A summary of the information was shown in Table 2 .

First, in terms of risk variation by gender, women generally perceive a higher risk to food safety than do men [6-8]. Second, in terms of variation according to age, older people perceive a higher risk than do the young $[6,7]$. Third, as for variations according to income, Lin [6], Zepeda et al. [8] and Ishida et al. [9] found no supporting evidence, while Dosman et al. [7] concluded that the effect of income on the perception of risk is unstable. Finally, in terms of the variation between households with and without children, Lin [6], Dosman et al. [7] and Ishida et al. [9] found that compared to households without children, those with children tend to avoid risk relating to food safety. However, Zepeda et al. [8] did not observe any variations in the perception of risk in households with and without children.

Purchasing behavior to avoid health hazards is determined by the risk level perceived by a consumer. Therefore, if the level of risk perception of radioactive
Table 2 Results of previous studies about the impact of sociodemographic factors on perceptions of risk.

\begin{tabular}{|c|c|c|c|c|}
\hline \multirow{2}{*}{ Studies } & \multicolumn{4}{|c|}{ Variables } \\
\hline & Female & Age & Income & With child \\
\hline Lin (1995) & + & + & N.S. & + \\
\hline Dosman et al. (2002) & + & + & U.S. & + \\
\hline Zepeda et al. (2003) & + & N.S. & N.S. & N.S. \\
\hline Ishida et al. (2012) & & & N.S. & + \\
\hline
\end{tabular}

substances in tap water differs according to social demographic factors, such as age, gender, and the presence of children in the household, these factors may influence the bottled water purchasing behavior of consumers. Moreover, although the level of radioactive iodine detected at the water purification plant exceeded the standard for infants, it was below the standard set for adults. Therefore, purchasing behavior may not only differ according to whether there are children in the household, but may also depend on the age of the children.

The authors hypothesize the following relationship between hoarding resulting from vague anxiety and fears about shortages of inventory in the future and the attributes of consumers. Women are more prone to impulse buying [10]. Young people are also prone to these types of purchases [11]. Moreover, married individuals might be more likely to engage in hoarding to avoid vague anxieties and fears about future shortages of inventory than unmarried individuals and individuals with high incomes might be more likely to engage in hoarding because they have greater financial flexibility to avoid these shortages in the first place.

In addition, households that did not prepare for the disaster are more likely to engage in hoarding after the earthquake [12]. Therefore, it is possible that consumers who purchased small volumes of bottled water prior to the earthquake will still engage in impulse buying after the earthquake.

In this paper, the authors analyze how the variations 
in the volume of bottled water purchased before and after the earthquake differ according to the attributes of individuals. Note that while the potential harm from the tap water covers a wide range in that it potentially affects all households in the river zone of the affected area, it is difficult to imagine that it would have the same effect on all of Japan. Therefore, even if households have identical attributes or are located in different areas, it is highly probably that their risk responses are different. Put differently, it is assumed that risk variations in the bottled water purchasing behavior of consumers differ between the Tokyo metropolitan district, where the radioactive substances in the tap water were detected, and the Osaka metropolitan district, where the tap water was unaffected. Therefore, in this paper the kinds of different factors affecting the purchasing behavior of bottled water in each region after the earthquake also are clarified ${ }^{3}$.

\section{Model and Data}

In this paper, the authors analyze how the change in the purchased volume of bottled water before and after the earthquake differed depending on the attributes of individuals. Certainly, consumers would have purchased bottled water even if the earthquake had not occurred. Therefore, in order to discern the effects the earthquake had on the purchasing behavior for bottled water, it is necessary to deduct the estimated volume of bottled water purchased if the earthquake had not occurred from the volume of bottled water purchased after the earthquake. The authors consider the difference in the volume purchased in the year prior to the earthquake and the year following the earthquake as the variation range of the volume of bottled water purchased because of the earthquake. Estimates from the linear model below are used to analyze how the variation range of the volume of bottled water purchased before and after the earthquake differed

3 The Tokyo and Osaka metropolitan areas are respectively 200 and 600 kilometers from the Fukushima No. 1 nuclear power plant where the accident occurred. according to the attributes of an individual in Eq. (1):

$$
\Delta y=\alpha+\beta X+u
$$

where, $\Delta y$ indicates the variation between the total volume of bottled water purchased from March 2011 to February 2012 and the total from March 2010 to February 2011; $X$ is a matrix of explanatory variables that reflects the attributes of individuals; $\alpha$ is a constant term; $\beta$ is a vector of parameters to be estimated; and $u$ is the random error term.

For information on the purchasing trends of individuals, the authors obtained the data in the QPR (Quick Purchase Report) from Macromill Inc., a market research company ${ }^{4}$. Monitors who input information such as the brand, the number of items purchased, and the date and time of the scan provide the QPR data using portable barcode scanners immediately after product purchase. These are combined data of purchased product information collected via the Internet and the attributes of the monitors previously registered.

Therefore, using these data, the authors can ascertain information that could not be acquired from POS (point of sale) data, namely, the type of attributes consumers have, when and what volumes they purchased, trends in the volumes purchased by consumers, and changes in their purchasing behavior. However, the QPR data only record the volume of products actually purchased. Therefore, it can not keep track of information at the store side that POS data could provide; for example, whether the store has a certain product in stock. As a result, when QPR data are used, the authors should recall the fact that these data can not consider the latent demand for a product that the consumer could not buy. In fact, directly after the earthquake, a shortage of bottled water arose as supply did not keep up with the dramatic increase in demand.

The allocation of the number of monitors to each area is on the composition ratio of the area population

\footnotetext{
${ }^{4}$ There are some previous studies that used data from Macromill Inc. [13, 14].
} 
in the national census data, and attributes such as gender, age, marital status and living alone or cohabiting determine the sample size. Users can purchase monthly QPR data on volume purchased by monitor and brand. Therefore, using these data, the monthly changes in the volume of bottled water purchased and the purchasing behavior of each monitor can be observed.

Fig. 1 depicts the trends in the volume of bottled water purchased per consumer in the Tokyo and Osaka metropolitan districts between April 2009 and February 2012. As shown, the volume of bottled water purchased after the earthquake in March 2011 was higher than in the same month of the previous year (an increase of $197 \%$ on a year-to-year basis). Fig. 1 also shows that there is variation between the level of purchases in the Tokyo and the Osaka metropolitan districts (an increase of 133\% year to year). Moreover, Fig. 1 also shows that the extent of the increase in the purchased volume was greater and the period that influenced the purchase volume was longer in the Tokyo metropolitan district, where the influence of the earthquake was greater, and where radioactive substances were detected in the water supply. The information on the various attributes of the consumers used in the QPR survey-such as age, gender, prefecture of residence, married or unmarried, residential status, individual and household annual income, number of persons in the household, occupation, and age category of the youngest child - is available. The six age categories of the youngest child are as follow: infants (1 to 3 years, which are denoted as $Y C=1)$, preschoolers $(Y C=2)$, early elementary school years $(Y C=3)$, higher grades in elementary school $(Y C=4)$, junior high school student $(Y C=5)$, and high school student and technical college student $(Y C=6)$. The seventh and final category is households without children $(Y C=$ 7).

The authors conduct an analysis on how the changes in the volume of bottled water purchased

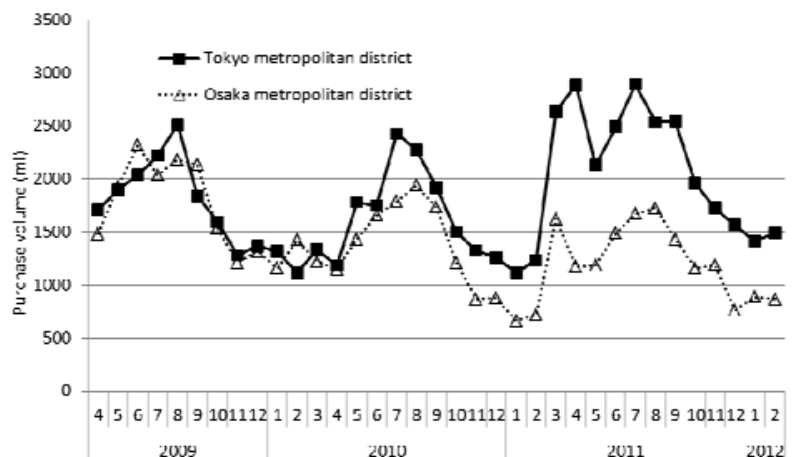

Fig. 1 Trends in the monthly purchase of bottled water per consumer.

before and after the earthquake differ depending on these variables. For this analysis, $\beta X$ in Eq. (1) is specified as follows in Eq. (2).

$$
\begin{aligned}
\beta X & =\beta_{1} c u m y+\beta_{2} \text { age } 1+\beta_{3} \text { age } 2+\beta_{4} c d \\
& +\beta_{5} c d s+\beta_{6} \text { sex }+\beta_{7} \sin +\beta_{8} \log (\text { inc })
\end{aligned}
$$

where, cumy is the cumulative volume of bottled water purchased from April 2009 to February 2011; agel is a dummy variable taking a value of one for individuals aged 34 years or younger, otherwise zero; age2 is a dummy variable taking a value of one for individuals aged from 35 to 49 years, otherwise zero; $c d$ is a dummy variable taking a value of one for individuals with children, otherwise zero; sex is a dummy variable taking a value of one for men, otherwise zero; $\sin$ is a dummy variable taking a value of one for single (unmarried) individuals, otherwise zero; and $\log (i n c)$ is the natural $\log$ of income per household member ${ }^{5}$.

In addition, as the volume of bottled water purchased could vary according to not only whether there are children in the household, but also the ages of the children, the authors include the age of the youngest child to verify if changes in purchasing behavior are observed when the youngest child's age is less than or greater than a certain age. As described below, the dummy variable $c d s$ takes a value of one when the youngest child's age category $Y C$ is equal to or less than $m$ in Eq. (3).

$$
c d s=1 \text { if } Y C \leq m \text {; otherwise } c d s=0 .
$$

\footnotetext{
5 The authors specify income in logarithms as the sample incomes are widely dispersed.
} 
In other words, $c d$ is one and $c d s$ is zero for individuals where the age of the youngest child is greater than $m$, and both $c d$ and $c d s$ are one if the age of the youngest child is less than or equal to $m$. In contrast, both $c d$ and $c d s$ are zero for consumers without children.

The threshold value $m$ that minimizes Akaike's Information Criterion (AIC) is selected. AIC is a statistic that expresses the goodness of fit of the model, as follows in Eq. (4).

$$
\mathrm{AIC}=-2 \ln (L)+2 k
$$

where $L$ is the model likelihood and $k$ is the number of parameters. Table 3 provides the definition of each variable and some summary statistics.

For the model estimates, the authors divide the sample into individuals who live in the Tokyo metropolitan district and those who live in the Osaka metropolitan district, another of Japanese largest cities. For each group, the authors substitute Eq. (2) for Eq. (1), and estimate the model using ordinary least squares.

\section{Estimation and Discussion}

For the estimates, the threshold age of the youngest child first is determined, $m$. That is, the authors estimate the model in which $m$ is set as an integer value in the range of 1 to 6 and a model that does not include $c d s$. The value of $m$ that minimizes AIC then is selected. It is found that AIC is minimized when $m$ $=3$ for the Tokyo metropolitan district, and when the model does not include $c d s$ for the Osaka metropolitan district. This suggests there is a boundary that accounts for the difference in the purchase volume of bottled water in Tokyo. This lies between the youngest child in the early elementary school age category and the higher grades in the elementary school age category. Conversely, in Osaka, no observable variation in purchase volume was found according to the age of the youngest child.

Next, in order to exclude those variables that do not have significant estimated coefficients from the model, the authors select variables from all combinations of explanatory variables to minimize AIC. Then, in order to test for the possible presence of multicollinearity between the explanatory variables, the values for the VIF (variance inflation factor) were calculated. Table 4 provides the VIF values for the Tokyo and Osaka metropolitan district samples. As all of the VIF values

Table 3 Definition of variables and summary statistics.

\begin{tabular}{|c|c|c|c|c|c|c|c|}
\hline Variables & & Tokyo & & Osaka & & Total & \\
\hline$\Delta y$ & $\begin{array}{l}\text { Variation in annual purchase volume of bottled water before } \\
\text { and after the disaster }\end{array}$ & 9854 & - & 1407 & - & 7374 & - \\
\hline cumy & Purchase volume of bottled water (April 2009-February 2011) & 37143 & - & 34907 & - & 36486 & - \\
\hline agel & Under 34 years $=1$, otherwise $=0$ & 451 & $(21 \%)$ & 181 & $(21 \%)$ & 632 & $(21 \%)$ \\
\hline age 2 & $35-49$ years $=1$, otherwise $=0$ & 671 & $(32 \%)$ & 283 & $(32 \%)$ & 954 & $(32 \%)$ \\
\hline$c d$ & Households with child $=1$, without child $=0$ & 626 & $(30 \%)$ & 275 & $(31 \%)$ & 901 & $(30 \%)$ \\
\hline $\operatorname{sex}$ & Male $=1$, female $=0$ & 1063 & $(50 \%)$ & 423 & $(48 \%)$ & 1486 & $(50 \%)$ \\
\hline $\sin$ & Single $=1$, married $=0$ & 653 & $(31 \%)$ & 245 & $(28 \%)$ & 898 & $(30 \%)$ \\
\hline $\log ($ inc $)$ & $\begin{array}{l}\text { Natural logarithm of household income per household } \\
\text { member }\end{array}$ & 5.44 & - & 5.29 & - & 5.39 & - \\
\hline$Y C$ & Age category of the youngest child & & & & & & \\
\hline$=1$ & Baby $(1-3$ years $)=1$, otherwise $=0$ & 102 & $(5 \%)$ & 39 & $(4 \%)$ & 141 & $(5 \%)$ \\
\hline$=2$ & Preschooler $(4-6$ years $)=1$, otherwise $=0$ & 126 & $(6 \%)$ & 64 & $(7 \%)$ & 190 & $(6 \%)$ \\
\hline$=3$ & Early elementary school years ( $7-9$ years $)=1$, otherwise $=0$ & 97 & $(5 \%)$ & 43 & $(5 \%)$ & 140 & $(5 \%)$ \\
\hline$=4$ & $\begin{array}{l}\text { Higher-grade at elementary school }(10-12 \text { years })=1 \text {, } \\
\text { otherwise }=0\end{array}$ & 97 & $(5 \%)$ & 40 & $(5 \%)$ & 137 & $(5 \%)$ \\
\hline$=5$ & Junior high school $(13-15$ years $)=1$, otherwise $=0$ & 108 & $(5 \%)$ & 32 & $(4 \%)$ & 140 & $(5 \%)$ \\
\hline$=6$ & High school $(16-18$ years $)=1$, otherwise $=0$ & 96 & $(5 \%)$ & 57 & $(6 \%)$ & 153 & $(5 \%)$ \\
\hline$=7$ & No children $=1$, otherwise $=0$ & 1486 & $(70 \%)$ & 603 & $(69 \%)$ & 2089 & $(70 \%)$ \\
\hline$n$ & Sample size & 2112 & & 878 & & 2990 & \\
\hline
\end{tabular}


are small, it is confirmed that there is no harmful multicollinearity. Table 5 shows the results of the estimates for the full model and the minimum AIC model when $m=3$ for the Tokyo metropolitan district, while for the Osaka metropolitan district, the model does not include $c d s^{6}$. The most interesting findings in Table 5 are as follows.

In both the Tokyo and Osaka metropolitan districts, the sign of the estimated coefficient of cumy is significantly negative. This indicates that individuals who rarely purchased bottled water prior to the earthquake increased the volume purchased after the earthquake. This suggests that consumers who did not prepare in advance for the disaster were prone to hoarding behavior after the earthquake. This is consistent with the results in Kurihara et al. [12].

For the Tokyo metropolitan district, agel, $c d, c d s$, and sex were included in the minimum AIC model. The signs for the coefficient of agel and sex were significantly negative, showing that compared with individuals aged 35 years and over, those aged 34 years or younger were less prone to increasing their purchase volume, which was also the case for men compared with women. This could be because when compared with younger people, older people more strongly perceived a risk from the radioactive substances detected in tap water, as did women compared with men. This finding is consistent with the results in Lin [6] and Dosman et al. [7].

The sign of the estimated coefficient for $c d$ is significantly negative, the sign of the estimated coefficient for $c d s$ is significantly positive, and the sign for the sum of the estimated coefficients for $c d$ and $c d s$ is positive. In the model for the Tokyo metropolitan district, $m=3$ was selected for the minimum AIC model. Therefore, the dummy variable $c d s$ is 1 for consumers with children in the early elementary school year age category or younger, otherwise zero. Accordingly, among consumers in households with children, the sum of the coefficients of $c d$ and $c d s$ was used for consumers whose youngest child was aged in the early elementary school years age category or younger, while the coefficient for $c d$

Table 4 Variance inflation factors.

\begin{tabular}{lll}
\hline Variables & Tokyo & Osaka \\
\hline cumy & 1.01 & 1.02 \\
age1 & 1.60 & 1.55 \\
age2 & 1.60 & 1.55 \\
cd & 2.28 & 1.66 \\
cds & 1.88 & \\
sex & 1.01 & 1.01 \\
sin & 1.51 & 1.46 \\
$\log ($ inc $)$ & 1.15 & 1.13 \\
\hline
\end{tabular}

Table 5 Estimation results.

\begin{tabular}{|c|c|c|c|c|c|c|c|c|c|c|c|c|}
\hline \multirow{3}{*}{ Variables } & \multicolumn{6}{|c|}{ Tokyo } & \multicolumn{6}{|c|}{ Osaka } \\
\hline & \multicolumn{3}{|c|}{ Full model } & \multicolumn{3}{|c|}{ Minimum AIC model } & \multicolumn{3}{|c|}{ Full model } & \multicolumn{3}{|c|}{ Minimum AIC model } \\
\hline & Coef & $t$-stat & & Coef & $t$-stat & & Coef & $t$-stat & & Coef & $t$-stat & \\
\hline const & 8837.6 & $(0.73)$ & & 20580.9 & $(10.25)$ & ${ }^{* *}$ & -7642.5 & $(-0.83)$ & & -10204.5 & $(-1.22)$ & \\
\hline cumy & -0.17 & $(-15.87)$ & $* *$ & -0.17 & $(-15.83)$ & ** & -0.13 & $(-13.30)$ & ** & -0.12 & $(-13.33)$ & ** \\
\hline agel & -8436.0 & $(-2.30)$ & * & -8365.9 & $(-2.84)$ & $* *$ & 1316.8 & $(0.46)$ & & & & \\
\hline age2 & -2970.0 & $(-0.92)$ & & & & & 230.0 & $(0.09)$ & & & & \\
\hline$c d$ & -5562.4 & $(-1.42)$ & & -7003.8 & $(-2.01)$ & $*$ & -2437.6 & $(-0.94)$ & & & & \\
\hline$c d s$ & 13944.6 & $(3.09)$ & ${ }^{* *}$ & 13685.9 & $(3.09)$ & ** & & & & & & \\
\hline $\operatorname{sex}$ & -5488.2 & $(-2.30)$ & ${ }^{*}$ & -5430.1 & $(-2.28)$ & $*$ & 2416.6 & $(1.29)$ & & & & \\
\hline $\sin$ & -2120.8 & $(-0.67)$ & & & & & -3995.2 & $(-1.59)$ & & -2945.4 & $(-1.42)$ & \\
\hline $\log ($ inc $)$ & 2380.2 & $(1.11)$ & & & & & 2606.8 & $(1.57)$ & & 3171.7 & $(2.02)$ & $*$ \\
\hline Adj- $R^{2}$ & 0.11 & & & 0.11 & & & 0.17 & & & 0.17 & & \\
\hline AIC & 52077.3 & & & 52074.4 & & & 20457.0 & & & 20451.8 & & \\
\hline
\end{tabular}

$* *$ and $*$ indicate significance at the $1 \%$ and $5 \%$ levels, respectively.

${ }^{6}$ Estimates were made even for the model with $Y$ as the purchasing standard, but no significant results were obtained. 
was used for consumers with children whose youngest child was in the higher grades in elementary school or older. In other words, the signs for the coefficients of $c d$ and $c d s$ indicate that the volume purchased by individuals was as follows (in descending order): first, individuals with children in the early elementary school years age category or younger; then individuals without children; finally, individuals with children in the higher grades in elementary school or older. The authors use these results to consider that in households with small children (who are more susceptible to the effects of radioactivity than are adults) consumers perceived a higher risk from drinking tap water and so tended to increase their purchases of bottled water. On the other hand, in households with children in the higher grades in elementary school or older (who are less susceptible to the effects of radiation than children in the early elementary school year age and younger) and who tend to drink large volumes of water, the financial burden required to change from tap water to bottled water was significant. Thus, these households were less likely to increase their purchase volume of bottled water.

In the Osaka metropolitan district, $\sin$ and $\log ($ inc $)$ were selected for the minimum AIC model. While the estimated coefficient was not significant at the 5\% level, the sign for the coefficient of sin was negative, and single (unmarried) consumers were then less likely to increase their purchase volume ${ }^{7}$. This suggests that married consumers engaged in hoarding in order to avoid vague anxieties and fears about shortages of inventory in the future. The sign of the coefficient of $\log (i n c)$ was significantly negative, and

\footnotetext{
${ }^{7}$ There are various criteria available for selecting the best model, including the Bayesian and generalized information criteria and the principle of Occam's razor, i.e., minimizing the number of regressands. Moreover, the authors should note that AIC does not necessarily result in selection of the true model $[15,16]$. The results of the regression, however, are unaffected, irrespective of which criterion we choose. Moreover, when the authors exclude the variable "sin" from the model, the remaining variables, such as "cumy" and " $\log ($ inc $)$ ", have the same signs and significance levels as the model including "sin", even if the goodness of fit became worse.
}

the purchase volume increased with increasing income per household member. It is considered that the greater the financial flexibility an individual has, the more they can spend to avoid vague anxieties and fears about shortages of inventory in the future.

As described above, there were differences in the explanatory variables that describe the differences in purchasing behavior for bottled water after the earthquake between the Tokyo and Osaka metropolitan districts. That is, in Tokyo, the age of the consumer, gender, and the age of the consumers' children, affected their perception of risk concerning the safety of tap water, and this affected their purchasing behavior. In contrast, in Osaka, being married or unmarried and income, thought related to financial flexibility and the ability to spend to avoid anxiety or strong fears about shortages of inventory in the future affected their purchasing behavior.

These results show that consumers had different motives for increasing their purchases of bottled water in Tokyo, which was near the site of the nuclear accident and where radioactive substances were actually detected in the water supply, and Osaka, which was far from the site of the accident and where the water supply was not affected.

\section{Conclusions}

This paper analyzed what types of individuals increased their purchases of bottled water around the time of the earthquake using scanned individual data. The following results were obtained. First, consumers who purchase less bottled water before the earthquake tend to increase the volume purchased after the earthquake. Second, the motives for purchasing bottled water after the earthquake differed between consumers in the Tokyo and Osaka metropolitan districts. Our results will contribute to making a policy to ensure stable supply of the necessities of life.

As a final point, the authors should mention the issues not fully addressed in this paper. First, the QPR data used in this analysis cannot take into account 
latent demand. In fact, directly after the earthquake, a shortage of bottled water occurred and limitations in supply restricted the purchase volume. Second, because of the limits of the data, variations in the changes in purchase volume over time according to consumer attributes could not be analyzed. In the data used in this analysis, the volumes for many samples were zero in most months. Therefore, it was difficult to clarify the variations in changes among consumers over time using panel analysis. If the authors could clarify not only different attributes in the changes in purchase volume clarified in this paper, but also the variations in purchase volume over time associated with individual attributes, then these may provide more detailed information for distribution management policy during a disaster. The authors hope to address these issues in future research, including areas such as the data and estimation methods that we could use.

\section{References}

[1] E.D. DeLorme, M.G. Zinkhan, C.S. Hagen, The process of consumer reactions to possession threats and losses in a natural disaster, Marketing Letters 15 (4) (2004) 185-199.

[2] M.E.J. Pennings, B.D. Grossman, Responding to crises and disasters: The role of risk attitudes and risk perceptions, Disasters 32 (3) (2008) 434-448.

[3] P.M. Azanza, C.I. Basman, Consumer acceptance of quick-cooking rice as food for use in a disaster, Journal of Consumer Studies \& Home Economics 23 (4) (1999) 225-230.

[4] Z.J. Sneath, R. Lacey, A.P. Kennett-Hensel, Coping with a natural disaster: Losses, emotions, and impulsive and compulsive buying, Marketing Letters 20 (1) (2009) 45-60.

[5] G. McKinnon, M.E. Smith, H.K. Hunt, Hoarding behavior among consumers: Conceptualization and marketing implications, Journal of the Academy of Marketing Science 13(1-2) (1985) 340-351.

[6] C.T.J. Lin, Demographic and socioeconomic influences on the importance of food safety in food shopping, Agricultural and Resource Economics Review 24 (2) (1995) 190-198.

[7] M.D. Dosman, L.W. Adamowicz, E.S. Hrudey, Socioeconomic determinants of health- and food safety-related risk perceptions, Risk Analysis 21 (2) (2002) 307-318.

[8] L. Zepeda, R. Douthitt, Y.S. You, Consumer risk perceptions toward agricultural biotechnology, self-protection, and food demand: The case of milk in the United States, Risk Analysis 23 (5) (2003) 973-984.

[9] T. Ishida, N. Ishikawa, M. Fukushige, Negative spillover effect on US pork and vegetable caused by the BSE outbreak, Journal of Food Research 1 (2) (2012) 32-44.

[10] A. Coley, B. Burgess, Gender differences in cognitive and affective impulse buying, Journal of Fashion Marketing and Management 7 (3) (2003) 282-295.

[11] E.K. Ketzenberger, L. Forrest, Impulsiveness and compulsiveness in alcoholics and nonalcoholics, Addictive Behaviors 25 (2000) 791-795.

[12] S. Kurihara, A. Maruyama, A.E. Luloff, Analysis of consumer behavior in the Tokyo metropolitan area after the Great East Japan Earthquake, Journal of Food System Research 18 (4) (2012) 415-426.

[13] D. Kim, P. Sugai, Willingness to pay for digital contents in Japan, Economics Bulletin 30 (3) (2010) 1745-1752.

[14] K. Nakayachi, The unintended effects of risk-refuting information on anxiety, Risk Analysis, in press.

[15] J. Shao, An asymptotic theory for linear model selection, Statistica Sinica 7 (1997) 221-264.

[16] H. Leeb, M.B. Pötscher, Model selection and inference: Facts and fiction, Econometric Theory 21 (2005) 21-59. 